\title{
The Relationship between Scholarly Teaching and SoTL: Models, Distinctions, and Clarifications
}

Michael K. Potter

Univrsity of Windsor, pottermk@uwindsor.ca

Erika D.H. Kustra

University of Windsor, kustraed@uwindsor.ca

\section{Recommended Citation}

Potter, Michael K. and Kustra, Erika D.H. (2011) "The Relationship between Scholarly Teaching and SoTL: Models, Distinctions, and Clarifications," International Journal for the Scholarship of Teaching and Learning: Vol. 5: No. 1, Article 23.

Available at: https://doi.org/10.20429/ijsotl.2011.050123 


\title{
The Relationship between Scholarly Teaching and SoTL: Models, Distinctions, and Clarifications
}

\author{
Abstract \\ We examine, through conceptual analysis and investigation of the available literature, some commonly \\ assumed models of the relationship between SoTL and scholarly teaching, demonstrate how those models \\ fare against the conceptual and empirical evidence, and propose an alternative that better represents the \\ concepts involved. Both our definitions and the model we choose to represent their relationship impact our \\ decisions regarding policies, programs, and resources. If the assumptions behind these practices are not \\ warranted, our reflexive use, dissemination and propagation of these practices must be questioned.

\section{Keywords} \\ Scholarship of teaching and learning, Scholarly teaching, Philosophy of higher education, Conceptual analysis

\section{Creative Commons License} \\ Creative \\ This worksis licensed under a Creative Commons Attribution-Noncommercial-No Derivative Works 4.0 \\ Attenipstion- \\ Noncommercial- \\ No \\ Derivative \\ Works \\ 4.0 \\ License
}




\title{
The Relationship between Scholarly Teaching and SoTL: Models, Distinctions, and Clarifications
}

\author{
Michael K. Potter \\ University of Windsor \\ Windsor, Ontario, Canada \\ pottermk@uwindsor.ca \\ Erika Kustra University \\ of Windsor Windsor, \\ Ontario, Canada \\ kustraed@uwindsor.ca
}

\begin{abstract}
We examine, through conceptual analysis and investigation of the available literature, some commonly assumed models of the relationship between SoTL and scholarly teaching, demonstrate how those models fare against the conceptual and empirical evidence, and propose an alternative that better represents the concepts involved. Both our definitions and the model we choose to represent their relationship impact our decisions regarding policies, programs, and resources. If the assumptions behind these practices are not warranted, our reflexive use, dissemination and propagation of these practices must be questioned.
\end{abstract}

Keywords: Scholarship of Teaching and Learning, Scholarly Teaching, Philosophy of Higher Education, Conceptual Analysis

\section{Introduction ${ }^{\mathrm{i}}$}

Although it has been nearly twenty years since Boyer popularized the scholarship of teaching and learning (SoTL) in Scholarship Reconsidered, unsupported assumptions abound, particularly regarding the relationship between SoTL and scholarly teaching. Some assume that scholarly teaching is coextensive with, or subsumed within, SoTL. Others believe that scholarly teaching is a step on the road to SoTL, the latter conceived as the apex of a developmental process. A few assume that people become scholarly teachers by first engaging in SoTL research, or that scholarly teaching, SoTL, and effective teaching provide mutual support.

Most importantly, many in the closely intertwined educational development and SoTL communities assume that both SoTL and scholarly teaching actually lead to better teaching and learning.

This article examines some commonly assumed models of the relationship between SoTL and scholarly teaching, demonstrates how those models fare against the conceptual and empirical evidence, and proposes an alternative, the stratified magisteria model, that better represents the concepts involved. 
What is scholarship of teaching and learning? What is scholarly teaching? How are they related? Both our definitions and the model we choose to represent their relationship matter, we argue, because they impact our decisions regarding policies, programs, and resources. The assumption that scholarly teaching and SoTL are directly related to improved teaching, and thus improved learning, has taken hold of higher education and is now shaping practice. Across the academic landscape SoTL projects, grants, communities, and institutes are being created, even in a time of overall funding cutbacks. Initiatives to promote scholarly teaching are also common, but less public, and typically ad hoc rather than systematic. If the foundational and motivational assumptions behind these practices are not warranted, our reflexive propagation of them must be questioned.

\section{Defining Scholarly Teaching and the Scholarship of Teaching and Learning}

Definitions are necessary to break down the delusion that we all mean the same things just because we are using the same terms. The definitions proposed below have been particularly influenced by Boyer (1990), Shulman (1999 and 2001), Hutchings and Shulman (1999), Kreber (2000, 2002a, 2002b, 2003, 2005), Richlin (2001), Shulman (2001), Pace (2004), Richlin \& Cox (2004), Allen \& Field (2005), and Hunt et al (2009).

We define scholarship of teaching and learning (SoTL) as:

the systematic study of teaching and learning, using established or validated criteria of scholarship, to understand how teaching (beliefs, behaviours, attitudes, and values) can maximize learning, and/or develop a more accurate understanding of learning, resulting in products that are publicly shared for critique and use by an appropriate community.

Note that all elements of the definition specify necessary conditions. That is, an activity does not meet our definition of SoTL unless each of its conditions is met. Together, this set of conditions is also sufficient. That is, any activity that meets all of these conditions is considered SoTL; nothing more is required.

The activity must be a systematic study using established or validated criteria of scholarship rather than mere reflection or haphazard, ad hoc gathering of information, because systematic study better suits the meanings long associated with the term "scholarship". Systematic study is deliberate, planned, intentional, occurring over time and refined as necessary. Such study, when informed and guided by adequate criteria validated by disciplinary history or other means (for instance, logically validated or validated in relation to a gold standard) provides a greater likelihood that trustworthy information will be created and disseminated. A study may be disciplinary or interdisciplinary, but if disciplinary it should use the criteria that partially constitute what it means to conduct research in that discipline; if one's SoTL project is intended to take the approach of cognitive science, the criteria of cognitive science should be used.

That information is intended to be publicly shared for critique and use by an appropriate community, generally as some sort of product - a conference presentation, a book, a paper, an internet resource, a documentary. That, too, follows from the meanings of scholarship (Shulman, 1987; Richlin, 2001; Trigwell and Shale, 2004). One's colleagues in the scholarly community may then use that work, refine it, replicate it, build on it, relate it to the work of others. As Antman and Olsson (2007) write, "If university teachers do not embrace and practice scholarship within the area of teaching and learning important and innovative work will continue to be private and undocumented, not available for scholarly peer review, 
scrutiny and feedback, not made public in a form others can build on, and consequently lost to the academic community".

The object of study is teaching and learning, by definition. Trigwell and Shale (2004) call this the "descriptive" aspect of SoTL, concerned with "understanding, categorizing, defining and describing" teaching and learning phenomena.

Furthermore, the goal of the study is either a better understanding of how teaching (beliefs, behaviours, attitudes, and values) can maximize learning, and/or a more accurate understanding of learning. Although a variety of possible "purposive aspects" of SoTL have been proposed over the years (Trigwell and Shale, 2004), we focus our definition on these two, for without them we have generic educational research, not SoTL. Just as all maples are trees though not all trees are maples, all SoTL is educational research though not all educational research is SoTL. SoTL is differentiated from other forms of educational research by its narrow focus on, and goal of eventually improving, teaching and learning (and by its near-exclusive attention to higher education, thus far). There is a direct benefit to the researcher as learner, a less direct benefit to those who consume the products generated, the scholarly teachers, and ideally an indirect benefit to the students of such teachers as well.

Ideally, SoTL should originate in critical reflection as well. Critical reflection is an aspect of a scholarly life or scholarly personality - but not necessarily an aspect of scholarship. People who are not critically reflective, for instance, can meet all of the necessary conditions specified for SoTL. Furthermore, it is possible that some SoTL originates not in critical reflection, but in the need to address an institutional or disciplinary need, an experiment or foray into a new world of research, even an attempt to impress tenure and promotion committees. Thus, we have not included this condition in our definition; we consider a foundation in critical reflection an ideal but not a necessary condition.

Now the other half of our conceptual pair. We define scholarly teaching as:

teaching grounded in critical reflection using systematically and strategicallygathered evidence, related and explained by well-reasoned theory and philosophical understanding, with the goal of maximizing learning through effective teaching.

Note, again, that all elements of the definition specify necessary conditions that must be met for teaching to count as scholarly, according to our definition. As with the definition of SoTL, this set of conditions is sufficient. That is, any activity that meets all of the conditions specified by this definition is considered scholarly teaching.

The activity must be grounded in critical reflection. As noted above, critical reflection is an aspect of a scholarly life or scholarly personality, a function of one's identity. It is difficult to apply the label of "scholarly" to someone who is not reflective; at best that person is well-read. Similarly, scholarly teaching is closely tied to one's identity as a teacher. Scholarly teachers hold themselves and their work up to rigorous standards as objectively as possible, allowing for positive and negative discoveries regarding their teaching effectiveness. These discoveries provide evidence that, upon analysis and evaluation, informs and motivates intentional refinement. Critical reflection is not necessarily wedded to any particular ideological position (as it is for Stephen Brookfield). Nor is it reflected in the popular sense of wondering, thinking about, or navel-gazing. 
Such critical reflection must use systematically and strategically-gathered evidence including, as noted, evidence about oneself gathered through critical reflection. Yet this is but one type of evidence among others; much of the evidence a scholarly teacher will use is drawn from SoTL literature, from the scholarly community of SoTL researchers to which he or she may belong, as well as from the discoveries of other scholarly teachers - a community that overlaps, but is not co-extensive with, the community of SoTL researchers. The more evidence we can gather, the greater our chances of developing as effective teachers - and we cannot consider ourselves scholarly in any endeavour unless we systematically and strategically gather evidence relevant to that endeavour. The notion of a scholarly teacher who lacks, and does not seek to obtain, evidence about effective teaching and learning is conceptually incoherent. As noted in the definition of SoTL, the systematic and strategic aspects of that evidence-gathering distinguish scholarly activity from ad hoc activity. Following Boyer, many have assumed - and a few have argued - that effective pedagogical growth depends on being scholarly in one's development, which typically means taking an evidence-based approach (Trigwell et al, 2000; Kreber, 2000 and 2002; Healey, 2000 and 2003; Trigwell and Shale, 2004).

Since all information must be related and explained in order to become evidence, scholarly teachers must relate and explain the evidence they gather using well-reasoned theory and philosophical understanding. This is frequently done unconsciously, haphazardly, poorly. But the scholarly teacher does it deliberately, carefully reasoning out the relationships between phenomena, creating meaning from the information available, making connections between this set of information and information in other realms, trying to tease out mechanisms that could explain why things work the way they do - in all cases building on the work of others. It is through effective theorizing that evidence can be used to inform development and predict likely results of application to practice. Furthermore, underlying each concept used in evidence and theory are a host of philosophical assumptions that impact effective practice, that shape approaches, direct implications, and specify relationships. These philosophical underpinnings must be surfaced, examined, critiqued, and changed when necessary.

Although teaching in itself is neither a scholarly nor effective activity, it is likelier to be both if it is driven by intentionality. Scholarly teaching is motivated by the goal of directly maximizing learning through effective teaching. Teaching is effective insofar as it maximizes and enhances learning more often than not. Constant, universal success cannot be required because it is beyond the ability of human beings; myriad variables impact the effectiveness of teaching, some of which are beyond a teacher's control. Hattie (2003) found that, of the 14 factors that most influence student learning, three were beyond the control of individual teachers (though a teacher may still mediate their effects): students' prior cognitive ability/learning, students' disposition to learn, and parental involvement. Six other factors with a smaller influence on student learning are also out of a teacher's control: peer effects, institutional aims and policy, affective attributes of students, physical attributes of students, ability grouping, and finances.

Whatever the contextual variables, intentionality, a reflective and evidential basis, and theoretical understanding increase one's ability to adapt to whatever contingencies obtain. The goal of scholarly teaching is not mere enjoyment for the teacher; it is inseparable from a motivation to discover what may enhance the learning of one's students. This condition will only seem necessary to those who have made the shift from a teaching-centred paradigm to a learning-centred paradigm, a shift that we assume is an inescapable consequence of scholarly development in teaching. 
Once clarified, our definition of scholarly teaching, we believe, is noncontroversial. It seems to be consistent with common speech about scholarly teaching, and though explicit definitions are not as common as they are for SoTL, ours is consistent with what is out there. Hunt et al, for instance, define scholarly teaching as "the reflective practice informed by the literature, teaching experience, or consultation - of applying theories of teaching and learning to the act of teaching. The goal of scholarly teaching is to improve one's teaching through thoughtful analysis of what is effective and not effective in one's practice" (Hunt et al, 2009). Our conception of scholarly teaching is also consistent with Kreber and Cranton's (2000) "third perspective" of SoTL, which they adapted from Menges and Weimer (1996). Furthermore, aspects of our definition of scholarly teaching are drawn from Boyer's (1990) conception of "scholarship of teaching" in Scholarship Reconsidered.

Nevertheless, some may take issue with the notion that one can be scholarly without making one's teaching available for public scrutiny (Trigwell et al, 2000; Trigwell and Shale, 2004). As the Carnegie Academy for the Scholarship of Teaching noted, this is an aspect of scholarship (Shulman, 1998). Yet scholarship and scholarly practice are not identical. If one meets each of the conditions specified above for scholarly teaching, there is no reason to disqualify that person from bearing the label of "scholarly teacher" merely because the practices and strategies are not written up for publication in a journal, videotaped for peer review, or even presented in a teaching dossier - though these latter conditions are important if that teacher's work is to be incorporated into scholarship.

Whereas the act of making one's discoveries public is contained within the concept of scholarship, it is not necessarily involved in scholarly life or personality. A scholar of teaching and learning need not be a scholarly teacher, for the scholarship of teaching and learning does not require one to use the products of SoTL nor, even, to be a teacher at all. And a scholarly teacher need not be a scholar of teaching and learning either, for scholarly teaching does not require one to be involved in generating the artifacts used by oneself or any other scholarly teacher.

Aside from conceptual differences, we have empirical reasons to believe that scholarly teaching and SoTL are distinct constructs. A survey of instructors at a research-intensive university, for instance, found that characteristics of SoTL and scholarly teaching were highly correlated, but that individuals could exhibit characteristics of scholarly teaching alone, SoTL alone, or neither (Borin et al, 2008). Elements of the survey were replicated in a teaching focused institution and in this different environment, no correlation between characteristics of scholarly teaching and SoTL was found (Hunt et al, 2009). Finally, Healey (2000) also found a paucity of evidence that SoTL engagement by faculty correlated with better learning for their students. Thus, a close relationship between SoTL and scholarly teaching is not necessary; it is dependent, to an extent, on environment - and likely other factors besides.

If scholarly teaching and SoTL were co-extensive, or scholarly teaching was subsumed under SoTL, one would expect them to correlate with student course experiences similarly. Furthermore, one would also expect both to correlate with effective teaching, which is likely responsible at least in part for positive student course experiences. It is thus instructive to note that characteristics indicative of scholarly teaching appear to be associated with results that one would expect from effective teaching, while characteristics associated with SoTL do not.

This may seem to conflict with Brew and Ginns' research (2008), reporting that SoTL engagement improved student perceptions of teaching quality. However, the aggregate data obscure some important findings, for the conclusion can only be drawn if the concepts 
of scholarly teaching and SoTL are conflated. When indicators of scholarly teaching and SoTL are separated, different conclusions emerge. The researchers found that characteristics indicative of scholarly teaching - such as completing a course on teaching and learning or winning a teaching award - are significantly correlated with positive student course experience. However, characteristics indicative of SoTL - such as publishing books and articles about teaching and learning - were either uncorrelated or negatively correlated with positive student course experience (though the negative correlation was not statistically significant). Following Kreber and Cranton (2000), Brew and Ginns list four components of SoTL, one of which belongs to scholarly teaching ("reflection on and application of the work of educational researchers"), one to SoTL ("discovery research on teaching and learning"), and one that belongs to neither, but which is likeliest to follow from scholarly teaching ("excellence in teaching as evidenced by teaching awards and evaluations of teaching"). Brew and Ginns also cite evidence that development as a scholarly teacher (by, for instance, taking courses on pedagogy) increases student satisfaction and a more learning-centred perspective on teaching (see Lueddeke 2003; Gibbs and Coffey, 2004), but present this as though it were evidence of the effects of SoTL engagement on teaching. Furthermore, they note that Dearn et al (2002) found that pedagogy courses were primarily focused on developing teaching skills, rather than SoTL research skills. These differences indicate SoTL and scholarly teaching are two different concepts.

Following Hattie (2001), Brew (2006) also conflates "scholarship of teaching" with "research-led teaching", the latter being similar to our conception of scholarly teaching. Hattie's working group developed seven key criteria for this conflated concept - none of them directly relevant to SoTL, most of them directly relevant to scholarly teaching. Similarly, Rice (1992) presents three elements of "scholarship of teaching" that belong much more obviously to scholarly teaching: synoptic capacity, pedagogical content knowledge, and knowledge of how people learn. Andresen and Webb (2000) do the same thing, identifying "scholarship of teaching" as something emerging from someone with disciplinary pedagogical knowledge and a critically reflective stance.

The conceptual confusion behind the assumed supremacy of SoTL over scholarly teaching is often subtle. Richlin and Cox (2004) make the distinction fairly explicit, and significant, by noting that scholarly teaching and SoTL have different targets: whereas scholarly teaching is intended to directly affect teaching and learning experiences, SoTL is intended to contribute to a public body of information about teaching and learning.

Yet for every Richlin and Cox, there are a dozen others. In their article on the difference between SoTL and scholarly teaching, for instance, Allen and Field (2005) conceptualize scholarly teaching as practical knowledge and judgment that emerges from reflection on SoTL literature and teaching experiences, focused on effective teaching rather than student learning - while SoTL is conceived as activity that is focused on both effective teaching and student learning. How one can divorce effective teaching from student learning is not explained, not even recognized, which bespeaks confusion about the concepts being addressed.

Working from Richlin (2001), Martin (2007) defines scholarly teachers as "those who consult the literature, select and apply appropriate information to guide the teaching-learning experience, conduct systematic observations, analyze the outcomes, and obtain peer evaluation of their classroom performance". Note that Martin, too, partakes of conceptual confusion by defining scholarly teaching primarily in terms of research activities (literature reviews, selecting and applying information, observing, analyzing. While Martin recognizes the practical goal of scholarly teaching, speaking of it as an ideal for all teachers that is directly relevant to teaching and learning, she assumes the sublimation of scholarly 
teaching under SoTL as well, contrasting the deep understanding obtained through SoTL with the "surface evaluation" involved in scholarly teaching.

Trigwell et al (2000) found tremendous conceptual confusion between SoTL and scholarly teaching, but did not identify it as such. In fact, it is interesting to note that their study found that many people valued and emphasized characteristics of scholarly teaching over characteristics of SoTL. They took this muddle at face value and decided that all of the characteristics identified must be elements of SoTL, which they then shoehorn into four "dimensions". Like Brew and Ginns, Kreber (2003) found widespread confusion about what constituted SoTL, though such confusion was most pronounced among those identified as "experts". Also like Brew and Ginns, she did not recognize this confusion as a problem. The experts saw SoTL as a research activity and were unlikely to identify it with effective teaching, while "regular" academic staff were likelier to see it as a notion linked to the practice of effective teaching.

Conceptual clarification should serve a practical purpose. Ours is a desire to know whether scholarly teaching or SoTL initiatives are appropriate uses of limited funds. If they result in better learning through teaching, we have one justification. There may be others as well. There is a need, then, now that we have clarified the concepts involved, to delineate the relationship between scholarly teaching, SoTL, and effective teaching.

\section{Models and Conceptions of Scholarly Teaching}

It should be obvious at this point that scholarly teaching and SoTL (what Boyer called "scholarship of discovery") are dissimilar, though related, activities. One could say that both are intended to improve teaching and thus maximize student learning, but whereas that goal is direct in the case of scholarly teaching, it can only be indirect in the case of SoTL. The latter seeks understanding, and makes that understanding available to others through publicly shared products - which can be used by scholarly teachers to inform their teaching, potentially helping them teach more effectively.

\section{The Mono-Model}

The mono-model presents SoTL and scholarly teaching as co-extensive, as either the same construct or aspects of the same construct, indistinguishable or inseparable. The monomodel often carries an additional assumption: namely that SoTL and scholarly teaching are also identical with good or effective teaching. Morehead and Shedd (1996), for instance, conceive of SoTL as "teaching excellence", and Menges and Weimer (1996) see SoTL as the use of teaching and literature to inform practice. See also Bass (1998), Trigwell and Shale (2004), Pace (2004), and the website of the University of Wisconsin-Milwaukee; though the precise models assumed by these sources are unclear, they seem to be consistent with the mono-model. Boyer's (1990) conception of SoTL seems to posit it as coextensive with scholarly teaching, though there are complexities to take into account, as will be discussed shortly.

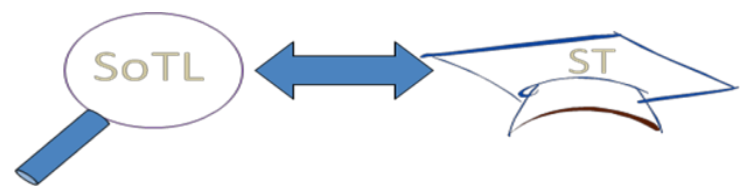

As we have seen, SoTL and scholarly teaching cannot be co-extensive concepts because they are not interchangeable. They have different meanings and implications; the necessary conditions of one are not the necessary conditions of the other. The mono-model is untenable. 


\section{Mutual Influence Model}

Some models postulate a more complex set of relationships, wherein SoTL and scholarly teaching influence each other, and both improve learning. These mutual influence models are compatible with the notion that the influence of scholarly teaching on learning tends to be more direct than the influence of SoTL on learning, allowing both to have some influence. An influential article by David Pace (2004), addressed to historians, seems to take such an approach, as do the websites of Indiana University-Bloomington and the University of Wisconsin-Milwaukee, though in the latter two cases the model assumed is unclear.



\section{ST Linear Development Model}

Most models are developmental and linear. A common model one hears assumed in conversations at educational development conferences is the ST linear development model, which assumes that scholarly teachers become SoTL researchers, whose SoTL research leads to improved learning. This model is less common in the literature, for reasons that will soon become clear.


\section{SoTL Linear Development Model}

More common is the model that assumes engagement in SoTL captures the interest of previously uninterested teachers who then use the information they have discovered to become scholarly teachers, which improves learning. For examples see Hutchings and Shulman (1999), McKinney (2007) and the University of Central Florida website.

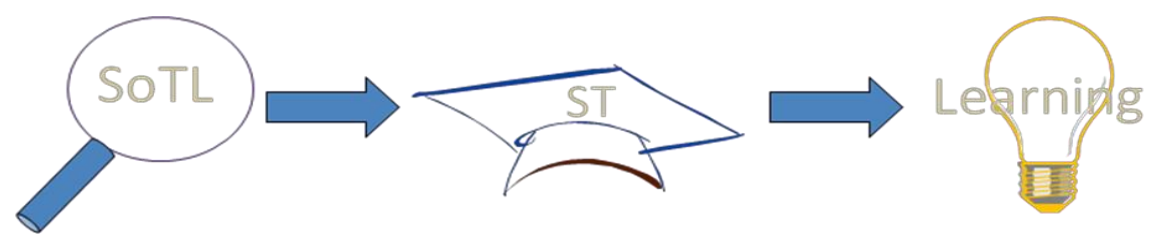


Sometimes the developmental hierarchy being assumed is unclear. Although Kreber's work seems to prioritize dissemination and peer review, thus implying a bias in favour of the ST linear development model, some of her work is consistent with the second as well. She writes that "academics who practice the scholarship of teaching engage in content, process and premise reflection on research-based and experience-based knowledge in the areas of instruction, pedagogy and curriculum, in ways that can be peer reviewed" (Kreber 2002a, p. 153). This is much like throwing apples in with oranges and claiming that the taste of the best apples features a hint of citrus.

\section{Generalized Magisteria Model}

A fifth model suggests that Scholarly Teaching and SoTL are captured by different sets of characteristics. While the characteristics may overlap within an individual, they do not necessarily. An individual may embody one, both, or none, as captured in this Venn diagram (adapted from Borin et al 2008). For example, an instructor may know the literature, be reflective about the need for change, but remain unable to put the literature into practice to maximize student learning. Alternatively, an individual might be effective at researching the impact of interventions, but may not be teaching, or may be more interested in the research than in teaching effectively or in a scholarly manner. Finally, there are effective teachers who have never engaged in SoTL, nor have they had access to the literature needed to inform the systematic reflection necessary for scholarly teaching.

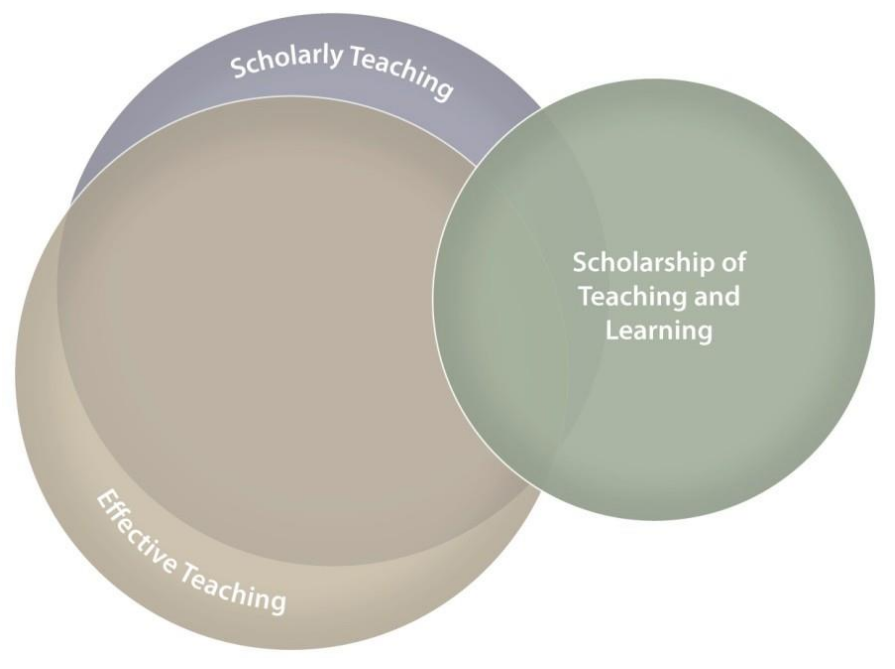

The surveys by Borin et al (2008) and Hunt et al (2009) provide empirical support for the conceptual and logical distinction between scholarly teaching and SoTL. Scholarly teaching is neither coextensive with, nor subsumed within, SoTL. In the Borin et al research at McMaster University, a research intensive university, a correlation was found between scholarly teaching and SoTL engagement. However, there were individuals who demonstrated one set of characteristics without the other. Further, in the research by Hunt et $a$ l at a teaching focused institution, Thompson River University, no such correlation was found.

Conceptually and empirically, we have adequate grounds to claim that both linear models, the mutual influence model, and the mono-model fail to capture the relationship between scholarly teaching and SoTL. Although they may demonstrate the paths some people follow to enter the worlds of scholarly teaching and SoTL, they do not sufficiently capture enduring and essential relationships between the two; the paths they indicate are possibilities among 
others. Connections between SoTL and scholarly teaching are not simple, but the concepts involved and the empirical evidence available support a model that posits scholarly teaching and SoTL as separate but overlapping magisteria, distinct worlds that may relate to each other in multiple ways, worlds that may have multiple entry points - none of them necessary.

The original spirit of SoTL, as captured in Boyer's report, may have been consistent with the conceptual confusion we are trying to disentangle, but we have logical-conceptual and empirical reasons to distinguish between SoTL and scholarly teaching. They are not the same construct, and of the two only scholarly teaching is directly correlated with teaching effectiveness. Once the concepts are distinguished, this finding does not come as a surprise. We are dealing with two distinct, though related, types of activities. The findings summarized from Borin and Kustra (2008), Hunt et al (2009), and Brew and Ginns (2008) are consistent with research that has found a null relationship between research excellence/productivity and teaching excellence/productivity.

SoTL, being a research activity, should not be expected to resemble scholarly teaching in a deep or essential way. Although several writers have put themselves through incredible conceptual and linguistic contortions to claim that teaching and research are the same sorts of activities, or two aspects of the same generalized activity, or activities related by common attributes of personality, they are clearly distinct (See, e.g., Feldman, 1987; Ontario Council on University Affairs, 1994; Brew and Boud, 1995a, 1995b; Hattie and Marsh, 1996; Zaman, 2004; Halliwell et al, 2008). Research is paradigmatically a prolonged process of inquiry. Certainly, yes, some very effective types of teaching involve or simulate prolonged inquiry, but not only are such methods decidedly not the norm, the goals, processes, tools, expectations, competencies, skills and goals of research and teaching remain distinct even if we take into account such exceptions.

It seems reasonable to ask, furthermore, whether the emphasis we place on either SoTL or scholarly teaching has an impact on how we perceive and interact with students. To the SoTL practitioner, it may be that students are likelier to be seen as objects of study, as facets of a research project who must be treated "ethically" (in the peculiarly legalistic sense used by research ethics boards), while to the scholarly teacher they may be likelier to be seen as discussion partners or junior colleagues to whom we are responsible for developmental support.

The distinction between SoTL and scholarly teaching resembles the distinction between tooland-die maker and machinist - the former is concerned with the production of materials for use by the latter. No one would seriously countenance the possibility that tool-and-die makers and machinists are necessarily identical, nor that being a machinist is merely a step on the road to becoming a tool-and-die maker. It is also similar to the difference between moral philosophy and moral practice. The practice of studying morality (moral philosophy) does not necessarily lead anyone to behave morally. Empirically, we have no evidence to indicate a necessary link, and conceptually there is no contradiction involved in conceiving of someone who studies morality acting horribly; thus the concepts must be distinct.

\section{The Overlapping Magisteria Model}

By building on the generalized magisteria model, and incorporating our definition of scholarly teaching, we postulate a more complex set of relationships and a finer-grained differentiation in an overlapping magisteria model. Our model is consistent with each of the above models for, while proposing a more complex representation of scholarly teaching, we also propose that there are multiple entry points from scholarly teaching into SoTL, and 
from SoTL into scholarly teaching. Thus, the paths specified above are all possible, but not necessary.

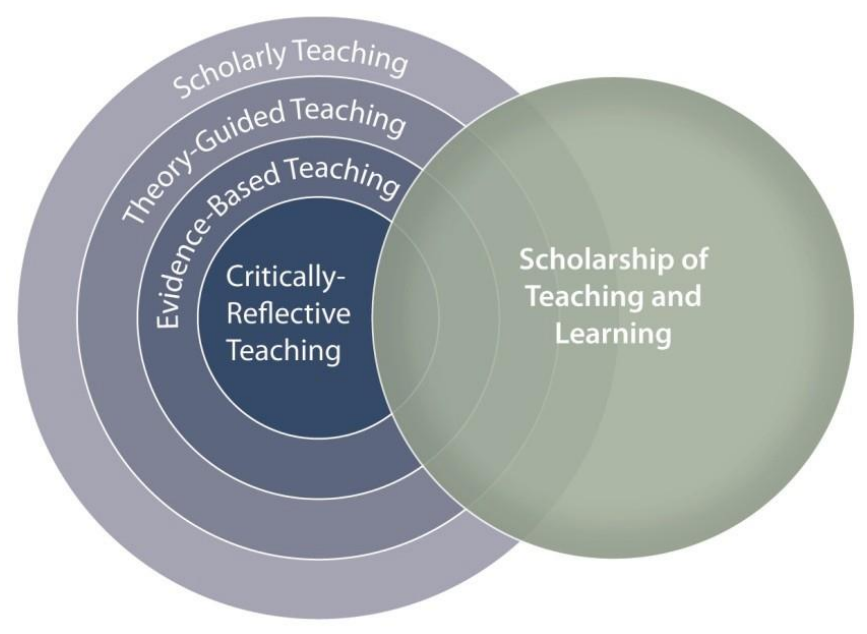

At the heart of both is critically-reflective practice, behaviours informed by critical reflection on one's beliefs, attitudes, values and practices, and their effects on student learning. In the case of SoTL, such reflection informs the direction and perspective of one's research and dissemination. Critically-reflective practice can provide an entry point from scholarly teaching into SoTL and vice versa, as one faces questions one cannot answer, unintended consequences, and the like. It is not enough to constitute scholarly teaching, however, given our definition.

The next aspect, evidence-based teaching, builds on critically-reflective practice by adding the dimension of an evidence base drawn from more than mere anecdote. At this level, one's reflections include evidence gathered from the scholarly literature and about one's own teaching (systematically and carefully rather than anecdotally), to inform decisions about how to teach, assess, design, create, and choose in the teaching context. This evidence is integrated into practice, as reflection helps the teacher discover where changes need to be made. This is still not enough for scholarly teaching, we argue, because evidence-based practice, on its own, is reactive and piecemeal, however systematically the evidence has been gathered. Evidence alone, no matter the quantity, does not lead to the adaptive character of scholarly teaching.

The third aspect, theory-guided teaching, takes that evidence and reflection and provides it with a framework to aid the understanding and create meaning, thereby bestowing the explanatory and predictive power necessary for adaptive practice. Well-grounded, conceptually coherent, rational theory makes sense out of, helps one sort, categorize, relate, and evaluate the information being gathered so that practice can be systematically adjusted for better efficacy. Some of what masquerades under the name of theory is more accurately termed mere speculation, however, so one must always bear in mind that theory worthy of the name must take into account the standards set above if it is to become an aspect of scholarly teaching. Nonetheless, theory-guided teaching that takes into account and explains the available evidence and the experiences constituting the object of critically reflective practice is still insufficient for our notion of scholarly teaching.

Note that both evidence-based and theory-guided teaching are research-based and research-informed, though the type of research associated with each differs. What turns 
such practice into scholarly teaching, finally, is praxis - a coherent teaching identity in which one's beliefs, values and behaviours are mutually supportive and consistent. One is a scholarly teacher if critically-reflective practice, evidence-based teaching, and theory-guided teaching are intentionally, systematically, and strategically integrated into one's identity and behaviours as a teacher. A scholarly teacher should by definition be more likely than others to teach effectively, that is, to maximize student learning. Nevertheless, among individual teachers, effective teaching may be found at any or none of the levels that constitute scholarly teaching. Even so, while scholarly teachers may use effective practices, what makes them scholarly are the reasons those practices are used. Thus, some who uses active learning approaches may be effective teachers without being also scholarly teachers if, for instance, those practices are used only because they seemed fun or they believe that is simply what is expected of them. Such reasons do not constitute a scholarly approach to teaching.

Although SoTL is not a necessary part of scholarly teaching, one may enter into the practice of SoTL at any level, because it is relevant to all of them in some way. At the level of reflective practice, one may be interested only in gathering information about, and reflecting on, the progress of one's students relative to a specific intervention. At the level of evidence-based teaching, one might review the literature on a given intervention, create and run a study on its use with one's own students, and thereby add to the information publicly available regarding that intervention. At the theory-guided teaching level, one may examine the foundational assumptions and implications of a set or practices, or relate one type of information to others in order to tease out potentially illuminating relationships, make necessary distinctions, predict consequences and implications, or undertake a conceptual analysis of language used by different sorts of practitioners.

Our model has elements in common with Kreber's (2002) taxonomy of pedagogical activities, though we do not claim that types of teaching we describe are hierarchically related in any developmental or progressive sense. One need not "progress" from the core of criticallyreflective practice to the level of scholarly teaching. One may, in fact, enter the model as a scholarly teacher. More importantly, Kreber's model shares the conceptual confusion we have attempted to dispel, insofar as it not only posits "scholarship of teaching" as the apex of a developmental process, but also sees that process as a description of the development of scholarly teachers, thus conflating two different concepts.

\section{Why the Model Matters}

Why should we care about the model of the relationship between SoTL and scholarly teaching? Put simply: misleading models lead to false assumptions. False assumptions lead to poor decisions, and, further, lead us to accept other false assumptions and misleading models, which leads to new sorts of poor decisions. The result, to narrow in on a small slice of a much larger pie, may be program, resource and policy decisions that a) have a negative impact on teaching and learning in higher education; b) are irrelevant to the quality of teaching and learning; and c) waste precious limited resources.

As it stands now, people at all levels of higher education are acting on misleading models that they have accepted for inappropriate reasons. Most people are not conscious of the models they assume; they are simply received and internalized. No matter. A model need not be consciously chosen to have implications for:

1. Programs offered by teaching and learning centres. With limited time and funding, should a faculty member be encouraged to enter SoTL research or develop as a 
scholarly and effective teacher? What will have the greatest impact on student learning?

2. Resource allocation. With limited budgets should centres spend their resources supporting more SoTL, more ST, a balance of the two? If a new position becomes available to a centre, is it better to invest in a SoTL expert or a scholarly teacher, if one cannot find a candidate who is both?

3. Policies set by institutions. Should tenure processes recognize dissemination of SoTL at a greater weight than evidence of scholarly teaching and effective student learning?

The distinctions we have drawn between the components of scholarly teaching in our inclusionary model are not likely to have a major impact on, say, policy-setting. The distinction between scholarly teaching and SoTL, however, should affect program decisions, resource allocation, and policy-setting as long as universities have limited financial and temporal resources.

\section{A Wolf in Sheep's Clothing}

There is another reason to take our choice of models seriously, one that is unacknowledged in SoTL literature. This concerns the value of scholarly teaching.

Regardless of Boyer's original intent, what is now called SoTL tends to fall into one of two categories: either what he called "scholarship of discovery" or a conflation of "scholarship of discovery" and "scholarship of teaching". The latter is more accurately termed "scholarly teaching". SoTL per se is research activity more-or-less traditionally conceived. As Trigwell and Shale write, SoTL models "tend to take aspects of scholarship rather than of teaching as their starting points, and to give priority to the construction and critical review of the knowledge base for teaching" (Trigwell and Shale, 2004, p. 523).

What explains the commonly assumed hierarchy? The goal, many authors assume, is for scholarly teaching to lead to publications and conference presentations, and that requires the transition from scholarly teaching into SoTL. That is, the hierarchy is assumed because the same stereotypical and unwarranted devaluation of "teaching' in favour of "research" that the concept of SoTL was meant to dissolve is unintentionally reinforced by its practitioners. All we have done is add SoTL to the other forms of research that are valued at the expense of scholarly (and effective) teaching.

This result flies in the face of Boyer's intent to enhance the status of teaching in higher education. By defining teaching as the scholarship of something, he inadvertently enabled the biases of the academic community to turn SoTL into yet another form of research prioritized over teaching.

As Brew (2006) recognizes, "a typical response to a policy of developing research-enhanced [scholarly] teaching and learning .... is to redefine existing practice in research-led terms, that is, to simply change the language used to talk about such practices". To some extent, this is what has happened with SoTL, which has been conflated with scholarly teaching. It has enabled people to dress existing biases in more tasteful clothing, a superficial gloss without meaningful change. According to Woodhouse (2010, p.3), Hutchings and Shulman (1999) "introduced the paradoxical concept of SoTL as a domain of scholarship which is distinct from that of research, but which nevertheless requires research to be defined as a 
domain of scholarship". In attempting to placate SoTL's critics they only added to the conceptual confusion while reifying the prestige of research over teaching. They rationalized this move by claiming that SoTL engagement would improve the teaching of SoTL researchers. Yet we have seen that this is not the case, and it is difficult to conceive of a mechanism by which that result could have been achieved.

As Woodhouse recognizes (p.3), "we do not necessarily act on new information or in response to rational arguments". Indeed, we have very powerful psychological defenses that prevent us from accepting information we do not want to hear. The reflective notion of scholarly teaching and the actual practices of acting on evidence and theory are essential for the transformation into effective and scholarly teachers, for it is only in living those concepts that we come to truly understand their full import (see Sharpe, 2004).

Roxa et al (2008) propose strategies for managing possible negative effects of engaging in SoTL within a "teaching and learning regime" that devalues teaching, all of which are quite sensible. What is missed, however, is the fact that the conflation of SoTL and scholarly teaching further delegitimizes scholarly teaching while SoTL rides the coat-tails of the established domain of respectability: research. Thus the old paradigm is reinforced.

Both SoTL capacity and scholarly teaching can be intentionally developed, and both can be developed at once, as Lund University's Pedagogical Academy seems to be demonstrating (see Antman and Olsson, 2007). Less systematic approaches to developing SoTL researchers who are also scholarly teachers could include forms of action research and SoTL learning communities that involve applications of literature to practice.

Although both scholarly teaching and SoTL capacity can be, ought to be developed, most universities lack the resources necessary to develop both at a large scale. Thus, decisions must be made - decisions that, we hope, will be guided by clear conceptualization and a commitment to avoid perpetual devaluation of scholarly and effective teaching.

\section{References}

Allen, M. \& Field, P. (2005). Scholarly teaching and scholarship of teaching: Noting the difference. International journal of nursing education scholarship. 2 (1).

Andresen, L.W. and Webb, C.A. (2000). Discovering the scholarship of teaching and learning. Richmond: University of Western Sydney, Hawkesbury.

Antman, L. and Olsson, T. (2007). A two-dimensional matrix model for analysing scholarly approaches to teaching and learning". In C. Rust (Ed.), Improving student learning through teaching (pp. 54-72), 19 (2). Oxford: The Oxford Centre for Staff and Learning Development.

Bass, R. (1999). The scholarship of teaching: What's the problem? Inventio: Creative thinking about learning and teaching, 1 (1), 1-10. Retrieved from http://doit.gmu.edu//Archives/feb98/rbass.htm.

Borin, P., Kustra, E., Martin, L., Sana, F., Savage, P., Vajoczki, S. (2008). Exploring the connections between scholarly teaching and the scholarship of teaching and learning. International Society for the Scholarship of Teaching and Learning conference. Edmonton, Alberta. 
Boyer, E.L. (1990). Scholarship reconsidered: Priorities of the professoriate. Princeton, NJ: Jossey-Bass.

Brew, A. (2006a). Learning to develop the relationship between research and teaching at an institutional level. In C. Kreber (Ed.), New directions for teaching and learning: No. 107 (pp. 13-22). San Francisco: Jossey-Bass.

Brew, A. (2006b). Encouraging the scholarship of teaching and learning in an institutional context. International Society for the Scholarship of Teaching and Learning conference.

Brew, A. and Boud, D. (1995a). Research and learning in higher education. In B. Smith and S. Brown (Eds.), Research, teaching and learning in higher education (pp. 30-39). London: Kogan Page.

Brew, A., and Boud, D. (1995b). Teaching and research: Establishing the vital link with learning. Higher education, 29 (3), 261-273.

Brew, A. and Ginns, P. (2008). The relationship between engagement in the scholarship of teaching and learning and students' course experiences. Assessment and evaluation in higher education, 33 (5), 535-545.

Bruff, D. (2009). The scholarship of teaching and learning (SoTL). Website of the Vanderbilt Center for Teaching. Retrieved from www.vanderbilt.edu/cft/resources/teaching_resources/reflecting/

Cross, K.P. \& Steadman, M.H. (1996). Classroom research: Implementing the scholarship of teaching. San Francisco: Jossey-Bass.

Fairweather, J. (2002). The mythologies of faculty productivity: Implications for institutional policy and decision making. The journal of higher education, 73 (1), 26-48.

Feldman, K.A. (1987). Research productivity and scholarly accomplishment of college teachers as related to their instructional effectiveness: A review and exploration". Research in higher education, 26, 227-298.

Glassick, C.E., Huber, M.T. and Maeroff, G.I. (1997). Scholarship assessed: Evaluation of the professoriate. Carnegie Foundation for the Advancement of Learning.

Halliwell, J. (2008). The nexus of teaching and research: Evidence and insights from the literature. Toronto: Higher Education Quality Council of Ontario.

Hattie, J. (2001). Performance indicators for the interdependence of research and teaching. In P. Shelley and G. Suddaby (Eds.), Understanding the Interdependence of Research and Teaching: Research Papers for the Vice-Chancellor's Symposium on the Research-Teaching Nexus. Palmerston North, New Zealand: Massey University.

Hattie, J. and Marsh, H.W. (1996). The relationship between research and teaching: A meta-analysis". Review of educational research, 66, 507-542.

Healey, M. (2000). Developing the scholarship of teaching in higher education: A discipline-based approach. Higher education research and development, 19 (2), 169-189. 
Healey, M. (2003). The scholarship of teaching: Issues around an evolving concept. Journal of excellence in college teaching, 14 (1), 2.

Ho, A.S.P. (2000). A conceptual change staff development programme: Effects as perceived by the participants". International journal for academic development, 3 (1), 2438.

Hunt, G., Templeman, E., Jones, J., Brewer, S., Baldwin, L., MacLennan, D. and Heaslip, P. (2009). Evolving concepts of scholarship: Dilemmas for a new university. Society for Teaching and Learning in Higher Education conference. Fredericton, New Brunswick.

Hutchings, P. and Shulman, L.S. (1999). The scholarship of teaching: New elaborations, new developments". Change, 31 (5), 10-15. Retrieved from http://www.carnegiefoundation.org/elibrary/scholarship-teaching-new-elaborations-newdevelopments

Indiana University-Bloomington website. (2009). What is SoTL at Indiana UniversityBloomington? Scholarship of Teaching and Learning at Indiana University Bloomington. Retrieved from www.indiana.edu/'sotl/whatis.html

Kreber, C. (2000). How university teaching award winners conceptualise academic work: Some further thoughts on the meaning of scholarship. Teaching in higher education, 5 (1), 61-78.

Kreber, C. (2002a). Controversy and consensus on the scholarship of teaching. Studies in higher education, 27, 151-167.

Kreber, C. (2002b). Teaching excellence, teaching expertise, and the scholarship of teaching. Innovative higher education, 27, 5-23.

Kreber, C. (2003). The scholarship of teaching: A comparison of conceptions held by experts and regular academic staff. Higher education, 46 (1), 93-121.

Kreber, C. (2005a). Reflection on teaching and the scholarship of teaching: Focus on science instructors. Higher education, 50 (2), 323-359.

Kreber, C. (2005b). Charting a critical course on the scholarship of university teaching movement. Studies in higher education, 30 (4), 389-405.

Kreber, C. and Cranton, P.A. (2000). Exploring the scholarship of teaching. The journal of higher education, 71 (4), 476-495.

Lindsay, R. and Jenkins, A. (1998). Do students suffer when teachers learn? HERDSA news, 20 (3), 14-16.

Marsh, H.W. and Hattie, J. (2002). The relation between research productivity and teaching effectiveness: Complementary, antagonistic, or independent constructs? The journal of higher education, 73 (5), 605-641.

Martin, L. (2007). Defining the scholarship of teaching versus scholarly teaching. Teaching and learning in higher education, 46, 1-3. 
McKinney, K. (2007). Enhancing learning through the scholarship of teaching and learning: The challenges and joys of juggling. San Francisco: Jossey-Bass.

Nelson, C. E. How could I do scholarship of teaching and learning?. Indiana UniversityBloomington website. Retrieved from http://php.indiana.edu/ nelson1/SOTLGenres.html

Pace, D. (2004). The amateur in the operating room: History and the scholarship of teaching and learning. American historical review, 109 (2), 1171-1193. Retrieved from www.historycooperative.org/journals/ahr/109.4/pace.html

Patrick, R. and Willis, D. (1998). Enhancing learning with research: A working paper". Victoria University of Wellington website. Retrieved from www.utdc.vuw.ac.nz/documentation/spectrum1/Paper11.htm.

Prosser, M. and Trigwell, K. (1999). Understanding teaching and learning: The experience in higher education. Buckingham: SHRE and Open University Press.

Rice, R.E. (1992). Towards a broader conception of scholarship: The American context. In T. Whiston and R. Geiger (Eds.), Research and higher education: The United Kingdom and the United States, (pp. 117-129). Buckingham: The Society for Research in Higher Education and Open University Press.

Richlin, L. (2001). Scholarly teaching and the scholarship of teaching. In C. Kreber (Ed.), New directions for teaching and learning: No. 86 (pp. 57-67). San Francisco: Jossey-Bass.

Richlin, L. \& Cox, M. (2004). Developing scholarly teaching and the scholarship of teaching through faculty learning communities. In M.D. Cox and L. Richlin (Eds.), New directions for teaching and learning: No. 97, (pp. 127-135). San Francisco: Jossey-Bass.

Roxa, T., Olsson, T., and Martensson, K. (2008). Appropriate use of theory in the scholarship of teaching and learning as a strategy for institutional development". Arts and humanities in higher education, 7, 276-294.

Scott, P. (2004). Knowledge work in a knowledge society: Rethinking the links between university teaching and research. The Higher Education Academy Learning and Teaching conference. The University of Hertfordshire.

Sharpe, R. (2004). How do professionals learn and develop? Implications for staff and educational developers. In D. Baume and P. Kahn (Eds.), Enhancing Staff and Educational Development, (pp. 132-153). London: Routledge Falmer.

Shulman, L.S. (1987). Knowledge and teaching: Foundations of the new reform. Harvard educational review, 36, 1-22.

Shulman, L. S. (1999). Taking learning seriously. Change, 31 (4), 10-17. Retrieved from http://www.carnegiefoundation.org/elibrary/taking-learning-seriously.

Shulman, L.S. (2001). Remarks at the teaching symposium for the cross endowed chair for the scholarship of teaching and learning. Normal, IL: Illinois State University.

Trigwell, K. and Shale, S. (2004). Student learning and the scholarship of university teaching. Studies in Higher Education, 29 (4), 523-536. 
Trigwell, K., Martin, E., Benjamin, J., and Prosser, M. (2000). Scholarship of teaching: A model. Higher education research and development, 19 (20). Retrieved from www.clt.uts.edu.au/Scholarship/A.Model.html.

University of Central Florida website. What is the scholarship of teaching and learning (SoTL)? The UCF Faculty Center for Teaching and Learning. Retrieved from www.fctl.ucf.edu/ResearchAndScholarship/SoTL/

University of Wisconsin-Milwaukee website. SoTL FAQ. UW System Leadership Site for the Scholarship of Teaching. Retrieved from www4.uwm.edu/sotl/help_support/faq.cfm.

uz Zaman, M.Q.. (2004). Review of the academic evidence on the relationship between teaching and research in higher education. Department for Education and Skills (DfES) Research Report RR506. London: DfES. Retrieved from http://www.dcsf.gov.uk/research/data/uploadfiles/RR506.pdf

Vajoczki, S., Borin, P., Kustra, E., Martin, L., Sana, F. and Savage, P. (2008). Scholarly teaching and scholarship of teaching and learning: Is there a connection? Society for Teaching and Learning in Higher Education conference. Windsor, Ontario.

Van Briesen, J. The research-teaching nexus - a priori truth or myth?". Tomorrow's Professor Msg. \#360. http://ctl.stanford.edu/Tomprof/postings/360.html

Weimar, M.E. (1997). Assumptions that devalue university teaching. The international journal for academic development, 2, 52-60.

Weimar, M.E. (2006). Enhancing scholarly work on teaching and learning: Professional literature that makes a difference. San Francisco: Jossey-Bass.

Woodhouse, Rosamund. (2010). Hype or hope: Can the scholarship of teaching and learning fulfill its promise? International journal for the scholarship of teaching and learning, 4 (1), 1-8. Retrieved from www.georgiasouthern.edu/ijsotl.

\footnotetext{
i The authors wish to thank participants at the SoTL Academy 2009 and Educational Developers Caucus 2010 conferences for their perceptive suggestions and criticisms when this paper was presented in workshop form, and Peter Marval, University of Windsor, for his graphical contributions.
} 